\title{
Building and Construction Classification Systems
}

\section{Lou, Eric Choen Weng}

Research Institute for the Built and Human Environment (BuHu)

University of Salford,

Greater Manchester, United Kingdom

\section{Goulding, Jack Steven}

Research Institute for the Built and Human Environment (BuHu) University of Salford,

Greater Manchester, United Kingdom

All correspondence shall be directed to:

Lou, Eric Choen Weng

e.c.w.lou@salford.ac.uk

Research Institute for the Built and Human Environment (BuHu)

University of Salford

R344 Maxwell Building

Greater Manchester

M5 4WT United Kingdom

T-0161 2953726 


\begin{abstract}
Within the construction industry, there is an increasing demand for information, especially with constantly changing products, technological developments and solutions pervading the marketplace. In this context, the idea of an 'ultimate classification system' has often been seen as a misnomer, or a bridge too far. However, whilst it acknowledged that the multiplicity of different classifications exist around the world, the incongruence and disparate nature of which could (and should) be revisited. This would help provide clarity, and unity, if nothing else; present a more holistic view of existing classification system in order to provide the basic rubrics for future classification systems.
\end{abstract}

\title{
Keywords
}

Building, Classification, Classification Systems, Construction

\section{Introduction}

The rapid development and dissemination of information technology within the construction sector demands international coordination of standards and classification systems (Saeed and Chaudhry, 2002; Wong et al., 2003). The uniqueness of the global construction industry is that it engages parties from a myriad of professions. Construction data, information, knowledge and intelligence exchanged between the various parties for the purpose of communicating design, construction and contractual matters are distinctive for different construction types, never 100\% similar (Chan and Kaka, 2007; Phua and Rowlinson, 2004). Both these factors combined produce a complex yet exciting challenge, classifying the construction industry in every country in the world. Classification within the construction sector is predominantly based on pragmatic tradition and national needs, but internationally applicable classification tables must be founded on a neutral conceptual framework.

Classification is fundamentally about information. It is about streamlining data to be turned into information and then into knowledge. To put it simply, now more than before, the growing use of modern communications has resulted in more electronic exchange of information about buildings - be it with project partners, with product suppliers, through the life-cycle of a building; both nationally and internationally. The organisation of this information is critical to its understanding and efficient usage. With these new needs and with the popularised use of computer systems, it matters less now how classifications are labelled but more the integrative nature of the concepts by which they are organised and then implemented.

This study of building and construction classification systems examines specific national and international case studies - taking into consideration national classification of contractors in Asia, Australia, Europe and the USA, benchmarked against internationally accepted groupings such as the International Standards Organisation (ISO) and the United Nations. In a nutshell, this paper reports on results of an ongoing investigation of coordinating classification systems for contractors, its demand and building information product modelling in the construction context, with established building classification systems.

\section{Classification}

Classification is a means to facilitate communication among construction professionals. Construction classification plays a major role in specifications, structuring of documents, and calculation of costs, among many others. The need for a generic classification system grows with the increased internationalisation of the construction market and the rapid development towards a computer integrated construction process based on computer aided product data modelling. These processes require standardised ways of describing construction artefacts, and classification is a means to achieve this. Nevertheless, classification within the construction sector is based on pragmatic tradition and national needs, but internationally applicable classification standards must be founded on a neutral conceptual framework. 
There is a lack of clarity and transparency in discussing the classifications, taxonomies and ontologies in research within the building and construction industry (van Rees, 2002). A general cause of this confusion is often caused by moving trends. There is much difference between the terms. The difference between a classification and a taxonomy, is that a taxonomy classifies in a structure according to some relation between the entities and that a classification uses more arbitrary (or external) grounds.

As an example of external grounds, glass forms part of a window and not every window has glass, so glass forms a subclass of a window. The decision to place glass in the window category is based upon data inherent to the entities, so this would be a piece of taxonomy (a taxonomy with a subclass hierarchy). On the other hand, the fundamental difference between a classification and an ontology is in the richness of information available. Both provide a list or structure of concepts or classification items. A classification basically stops at that point, as such it provides boxes with labels into which to put your items. Therefore, an ontology provides a lot of information about the concepts, including their relationships.

\section{Existing Classification systems}

One of the earliest forms of information classification systems for engineers is the Library Classification System (LCS), which enables engineers to search library information easily (Hoare, 1998). Various types of LCS exist, namely the Dewey Decimal Classification (DDC), Universal Decimal Classification (UDC) and the Library of Congress Classification (LCC) (Broughton, 2006; McCulloch, 2004). Both the DDC and UDC systems have hierarchical classification with decimal codes system, while the more recent classification systems such as the Samarbetskommittén för Byggnadsfrågor' $(\mathrm{SfB})$ and Construction Industry Classification System $(\mathrm{CI} / \mathrm{SfB})$ use the faceted code system. More advanced digital classification systems exist today, such as the International Standards Organisation (ISO/DIS) 12006-3, the United Nations Standard Products and Services Code (UNSPSC), the Norwegian Bygg Og Anlegg Referanseninliotek (BARBi), the Swedish Byggandets Samordning AB (BSAB), the MasterFormat system used in North America and many more. The latest developments of information integration are demonstrated in the OmniClass Classification System. International groupings references are taken as case studies, such as those used by the Building and Construction Authority (BCA) in Singapore, The Home Building Service (HBS) of New South Wales in Australia, The Contractors State License Board (CSLB) of California in the USA and the Works Branch, Development Bureau of Hong Kong SAR. Construction classification systems was first developed and used in Sweden more than 50 years ago; developments in North America and the rest of Europe only began 20 years later.

\section{Building and Construction Authority (BCA), Singapore}

The Contractors Registry in Singapore is administered by the Building and Construction Authority (BCA) to serve the procurement needs of government departments, statutory bodies and other public sector organisations. This Registry functions as an administrative body only for the public sector procurement. As such, business entities that are not registered with BCA are not precluded from conducting business as contractors or suppliers outside the public sector.

There are five major groups of registration heads, namely Construction Workheads (General buildings (CW1) and Civil engineering (CW2), Construction related workheads (CR), Mechanical and Electrical workheads (ME), Supply workheads (SY) and Maintainence Workheads (MW). The BCA classification is further broken down into seven (7) financial grades for the CW1 and CW2 groupings, and six (6) financial grades for CR, ME, SY and MW; no financial grading for CR03 (Demolition) and RW01 (Windows contractor) (BCA, 2007).

\section{Home Building Service (HBS), New South Wales, Australia}

The Government of New South Wales, Australia, under the Office of Fair Trading, established the Home Building Service (HBS) to take responsibility for the licensing and regulation of builders and tradespeople in the home building industry and specialist contractors across all industries. The HBS sets and maintains standards of competence for builders and tradespeople and issues licences and certificates for individuals and organisations in accordance to the Home Building Act 1989.

HBS enforces contractor licensing through a set of contractor licence categories - Bricklaying and Stonemasonry, Mechanical Services, Roof Plumbing, Slating and Tiling, Dry plastering, among others. No financial restriction or categorisation is imposed (Home Building Service, 2007).

\section{Contractors State License Board (CSLB), California, USA}


The Contractors State License Board (CSLB) was established in 1929 as the Contractors License Bureau under the Department of Professional and Vocational Standards. The CSLB is the California consumer protection agency charged with licensing construction contractors who work in the state, resolving consumer complaints, and enforcing state laws pertaining to contractors. CSLB certifies contractors in 46 categories and registers home improvement salespersons (Contractors State License Board, 2007).

\section{Works Branch, Development Bureau, Hong Kong SAR, China}

The Works Branch administers and oversees the construction industry of the Government of the Hong Kong SAR. Any firms wishing to be considered for inclusion in the List of Approved Contractors for Public Works and/or the List of Approved Suppliers of Materials and Specialist Contractors for Public Works for the purpose of carrying out government contracts must apply and obtain licence from the Work Branch.

The List of Approved Contractors for Public Works comprise of contractors who are approved for carrying out public works in one or more of the categories buildings, port works, roads and drainage, site formation and waterworks. Contractors within each category are further divided into Group A, B or C according to the value of contracts for which they are normally eligible to tender. (Works Branch, Development Bureau, 2007).

\section{Construction Industry Classification System (CI/SfB) (United Kingdom)}

Construction Industry Classification System ( $\mathrm{SfB}$ is from the Swedish "Samarbetskommitten for Byggndsfragor", translated as Joint Working Committee for Building Problems) or CI/SfB, is the UK version of the international $\mathrm{SfB}$ classification system administered by the Royal Institute of British Architects (RIBA). The system has been in operation for over 30 years and it remains the most widely used system in architectural specifies' product information libraries. The $\mathrm{CI} / \mathrm{SfB}$ is mainly used by designers and for product literature, Common Arrangement, organised by work sections in a previous attempt to unify classification.

The system is made out of five facets 'Table 0 ' refers to the UDC system, 'Table 1', 'Table 2' and 'Table 3' modifies the SfB system and 'Table 4' refers to the master lists of the International Council for Building Research (CIB). The facilities for civil engineering projects are related to 'Table 0 ', consisting of 9 categories, while 'Table 4' classifies the types of construction support systems, construction equipment included. (Ray-Jones and Clegg, 1991)

\section{United Classification (Uniclass) (United Kingdom)}

Unified Classification for the construction industry or in short Uniclass, is the product based on the ISO classifications standard, through the comparisons with $\mathrm{CI} / \mathrm{SfB}$, that is being widely used for a CICS (Construction Information Classification System). The general structure of the classification scheme in Uniclass is equipped with more discriminative facets and capable of classifying information for civil engineering works. In short, the Uniclass system improves and collaborate existing classification systems for the construction industry.

Uniclass is structured with a faceted classification system such as the $\mathrm{CI} / \mathrm{SfB}$ rather than a hierarchical classification system, such as MasterFormat. The general structure of Uniclass facets is grouped into fifteen main subjects. Facets A, B and C in the table are general summaries concerning information form or management field, while facets $\mathrm{D}, \mathrm{E}, \mathrm{F}, \mathrm{G}, \mathrm{H}$ and $\mathrm{K}$ consist of facilities, spaces, elements, and operations for civil and architectural works. Facets L, M, N, P and Q facets are useful to classify information concerning construction products, materials and attributes (Crawford et al., 1997).

\section{Common Arrangement of Work Sections (CAWS) (United Kingdom)}

The CAWS is used to define an efficient and generally acceptable arrangement for specifications and Bills of Quantities for building projects (Construction Project Information, 1987). It consists of a set of detailed work section definitions, all within a classification framework of Groups and Sub-groups. The CAWS classifies down to the level of work section titles forms 1 of the 15 tables of the Uniclass classification scheme. The National Building Specification (NBS) is structured in CAWS format. NBS provides a library of building product manufacturer details, used by over 18,000 specifiers in over 5,000 subscribing offices, with the aim to improve proprietary specification practice for both specifiers and manufacturers. 
CAWS includes about 360 work sections, reflecting the large range of specialists and subcontractors that now exist. In addition, CAWS classification lists a series of headings for preliminaries, from A1 - through to A5-. These cover general things such as information about the project, site, employer and consultants through to more detailed requirements on safety, security, method sequence and timing of the work, facilities and services and suchlike. The A2- section includes clauses that are contract-specific and contain details of the actual form of contract and how it will be completed (although they do not contain the contract itself). Sections A6- onwards relate to specific preliminaries for use in particular circumstances, such as demolition or site investigation/survey contracts.

\section{STABU LexiCon (Netherlands)}

The STABU LexiCon provides definitions and specifications of concepts which are of interest for the construction industry. The language used is defined in the (draft) international standard ISO 120063:2002 (Building construction - Organisation of information about construction works - Part 3: Framework for object-oriented information). STABU serves the Dutch construction industry, thus, Dutch is the 'natural' language to which the concepts are translated but also two English versions are provided UK English and North American English. The LexiCon development proposes a multi-lingual tool for management of construction terms, describing built objects and their association. It uses an objectoriented approach and built objects are described by component, function and quantity.

The LexiCon identifies physical objects and spaces as classes of interest for the construction industry, with a scope reaching from the largest construction works (e.g. an airport) to the smallest articles delivered by manufacturers (e.g. nails or sand). Each class is defined by a set of attributes and each attribute is a class in its own right. The STABU system has a relational database structure, which permits the user to work with the system in various ways. It is based on the assumption that each part of a project has its own identity (Cotton and Oliver, 1994).

\section{POSC/Caesar (Norway)}

POSC/Caesar is a joint initiative of the Petrotechnical Open Software Corporation and the CAESAR Offshore Project. The objective of the POSC/Caesar project is to develop a standardised product model for handling life-cycle information about oil and gas facilities. The product model is developed on the basis of the EPISTLE framework. The work has resulted in practical means for handling product information based on a data model and additional library classes. This project is of specific interest to the construction sector since it represents an attempt to create a computer based platform for integrated information management.

The data definition language for the POSC/Caesar approach is based on a subset of the concepts of the EXPRESS information modelling language. This subset of EXPRESS is called the POSC/Caesar Meta model; it is the most abstract POSC/Caesar model. The scope of the POSC/Caesar Data model is classes considered of importance for handling life-cycle information in a generic way about oil and gas facilities (POSC, 2007).

\section{Bygg Og Anlegg Referanseninliotek (BARBi) (Norway)}

BARBi is a project initiated by the Norwegian construction industry to establish a reference data library with a complete collection of all concepts and objects from the building and construction industry with associated properties and relationships. The library contains everything from complete constructions down to individual parts or products. Resources, activities and references to standards, classification tables and application protocols like IFC and STEP-APs are included in the library. The framework of ISO/DIS 12006-3 provides the necessary structure to add objects and their attribute and relationships along with multilingual capabilities. Each object and relation gets a unique ID, which can be referred to from other systems. This unique ID can have a central role in future e-commerce and will provide the possibility to compare objects between different information structures (Bell et al., 2004).

\section{Samarbetskommittén för Byggnadsfrågor' (SfB) (Sweden)}

In the years 1946-50 the technical secretariat of the Swedish SfB Committee (in Swedish 'Samarbetskommittén för Byggnadsfrågor', in English 'The Co-ordination Committee for the Building Trade') developed the first common classification system for the building sector, with the purpose to facilitate the communication between materials market, design and construction. The scope of the SfB system was restricted to the design and construction interface of the building process with the objective to 
create a registration system, which can be used not only for clauses concerning materials and workmanship but also for specifications of works, quantity estimates, documentation of building materials and price lists.

The SfB system is a faceted classification system consisting of three facets - Elements, Construction Activities and Materials. The system combines classified items in each facet to express a construction work item, where it can be used for drawing and construction cost items by a combination of facets. This $\mathrm{SfB}$ system is the basis of future classification system (Giertz, 1995).

\section{Byggandets Samordning AB (BSAB) (Sweden)}

BSAB Sweden was founded with the aim to promote coordination, communication and information within the building sector. In 1972, BSAB published a new classification system based on the SfB system, where the points of view from the installation sector and the use of the system in computer applications were considered; BSAB became part of the Swedish Building Centre. A further developed version of the system, which is still in use, was published in 1983.

The classification tables of BSAB 96 adhere to the ISO 12006-2 Framework standard. The tables in BSAB 96 contain subclasses of the main classes in the Framework. Both standards are based on common principles for building classification established already with the SfB-system from 1950. The present BSAB System contains two product classification tables, Product Table 1 and Product Table 2. In Product Table 1, the work sections of earthworks, buildings and building services are classified mainly with regard to their material content, but partly with regard to the type of labour required to produce them. Product Table 1 has 26 primary principal groups $(\mathrm{A}, \mathrm{B}, \mathrm{C}, \ldots \ldots . \mathrm{S})$ which are further subdivided. Most of the classification concepts are associated with product resources (SB-Rekommendationer, 1987).

\section{MasterFormat (North America)}

MasterFormat is a list of standardised numbers and titles for organising construction bidding and contract requirements, specifications, drawing notes, cost data, and building operations by work results. This standard does not establish design disciplines, trade jurisdictions or product classifications. Revisions are necessary over time to allow for new materials and technologies, increased use of databases, project lifecycle issues, expansion to non-building types of construction, and flexibility for future developments. This system is the most widely used standard for organising specifications and other written information for commercial and institutional building projects in the USA and Canada. The new 2004 edition is the most significant revision in its history.

Construction information in MasterFormat system consists of Groups, Sub-Groups and Divisions. There are 34 active Divisions plus 16 reserved Divisions, numbering from Division 00 to Division 49 . New divisions are included to allow more flexibility for specifying civil, process and other engineering work. Section Numbers and Titles are assigned for thousands of common work results in the system. The numbers generally have three pairs of numbers (6 digits), each pair defining a level of specificity. An optional fourth pair of numbers (Level 4) is used for when greater specificity is required. Additional numbers and letters can be added (Level 5) for user-assigned numbers. Spaces between pairs are optional and should be made with word processing 'hard space' function (MasterFormat, 2004).

\section{Yellow Pages, worldwide}

The Yellow Pages refers to a directory for businesses organised by the category of product or service. The directory is published annually and distributed for free to all residences and businesses within a given coverage area. The majority of listings are in plain small black text. The information contained in the Yellow Pages is essentially a commodity, thus, publishers often engage in product differentiation tactics, such as, overall comprehensive or up-to-date listings.

There is no standardisation of trades nor product classification among all the selected countries. Contents of the directory are different in all countries; Yellow Pages do not classify by hierarchy and do not code contractors. Classification is simple, but yet specific. The directory simply specifies and sorts trades in alphabetical order and lists the contractors in alphabetical order. The specified trades are different in every country directory as the Yellow Pages is driven by the industry and supplier of the specific country.

\section{Construction Information Classification System (CICS)}

The CICS for construction projects is designed with emphasis on information classification and cost management principles as its focal point. The CICS system consists of four faceted tables, which are 
classified into facilities, spaces, elements and operations by construction work types, in particular to construction projects. The classified items in the facility facets will be used to express total construction cost or a milestone network. The classification items in the operation facet can be applied to estimate unit work cost or to draw a detailed-network. Schedule planning to complete a product is develop inline with the path from facility to operation facets but the results from cost estimating process or resource mobilisation are summarised in the path from operation to facility facets. Items in the in lower classes are linked to the items in upper classes repeatedly (Kang and Paulson, 1997).

\section{Engineering Information Classification System (EICS)}

The EICS is exclusively designed and developed to facilitate information sharing throughout the planning, design, construction, and maintenance phases for engineering works of a construction project. EICS is somewhat similar to the work breakdown structure (WBS), a logical method for dividing a project into small, manageable components and always focuses on a product or process. The upper-level items are generally the final products, such as reports and the lower-level items are functional tasks to complete the products, such as drainage analysis. This system combines the three bases to classify all information in the engineering work; deliverable oriented, schedule oriented and resource oriented. The orientations correspond to the engineering project's output, process and input. With the three orientations built into the EICS, information collected are displayed in different perspectives and management control can be exerted at the output, process or input stage. The coding system of EICS includes 6 digits: the first 3 digits address the market unit, and the second 3 denote the technical elements. All digits use decimal numbers except the function (or fourth) digit, which is a letter of the alphabet. A project number is given at the beginning of an engineering project and that include the engineering project's construction type. Engineering works are often project specific and given in project number, thus, it does not take any digits in the coding system (Chang and Tsai, 2003).

\section{United Nations Standards Products and Services Code (UNSPSC)}

UNSPSC coding system is designed to serve the primary functions of recourse directory, where the identification of relevant suppliers of a specific product or service; reporting on the use of funds through expenditure analysis; product awareness through the integration of products or services into the common nomenclature that prospective customers use to search for products and services. The UNSPSC system is a hierarchical classification, having five levels. The levels allow users to search products more precisely as searches are confined to logical categories and eliminate irrelevant hits, and this allows higher management to perform expenditure analysis on categories that are relevant to the organisational situation (UNSPSC, 2007).

\section{International Standards Organisation ISO/DIS 12006-3}

The ISO/DIS 12OO6-3 version 3 consists of the specification of a taxonomy model, which provides the ability to define concepts by means of properties, to group concepts, and to define relationships between concepts. Objects, collections and relationships are the basic entities of the model. The set of properties associated with an object provide the formal definition of the object as well as its typical behaviour. Properties have values, optionally expressed in units. The focus is on the structure of the information and does not provide any rules or guidelines regarding the information content. The model has one Root entity from which the following three subtype entities inherit: Objects, Collections and the Relationships between them. The Root entity provides the ability to assign any set of names, labels, descriptions and references, in any language, to its derived types, as well as identities and dates. Objects are divided into Subjects, Activities, Actors, Units, Measures with Units and Properties. Subjects and Activities are the things and processes that are described. The others are description entities related to other Objects and themselves through Relationships. The ISO/DIS 12OO6-3 standards is described in the set of diagrams conforming to the EXPRESS-G notation and described formally in the EXPRESS data definition language specification (ISO, 2007).

\section{International Alliance for Interoperability - Industry Foundation Classes (IAI-IFC)}

The goal of IAI is enabling interoperability between AEC/FM applications from different software vendors. This goal is to be achieved through development of the IFC - objective to provide a framework for sharing information between different disciplines within the AEC/FM industry. Work on international 
IFC Model development started in 1996 and has continued through various releases $(1.0,1.5,1.5 .1,2.0)$ to the present.

The IFC Model architecture provides a modular structure for the development of model components, the 'model schemata'. There are four conceptual layers within the architecture, which use a strict referencing principle. Within each conceptual layer a set of model schemata are defined. The IFC are divided into four separate model levels: Resources Layer, Core Layer with Kernel and Core Extensions, Interoperability Layer, and Domain Model Layer. All the IFC schemas are developed using the EXPRESS data definition language (IAI-IFC, 2007).

\section{OmniClass Construction Classification System (OmniClass)}

OmniClass is designed to comprehend and organise the entire universe of knowledge within the North American AEC Industry, throughout the full life cycle of the built environment, from conception to demolition, and encompassing all forms of construction. OmniClass is intended to be the basis for organising, sorting, and retrieving information and deriving relational applications. The primary legacy systems from which several of the OmniClass Tables and content are drawn from include Uniclass, MasterFormat, UniFormat and EPIC (Electronic Product Information Cooperation). OmniClass version 1.0 is made up of the following 15 tables, each of which would describe different aspects of the physical world and the built environment and be capable of supporting computerised information storage and retrieval, interacting as a database and be searchable through a key word matrix composed of the terms of the tables (OCCS, 2001). Entries from different tables can be combined to classify and identify very discrete objects of the built environment (OmniClass, 2006).

The OmniClass development is an ongoing effort; in this sense, it may never be 'finished'. The constant innovation of products made available and design and construction techniques being employed by users in all sectors of the AEC industry mean that terminology and concepts that the OCCS will have to address will be in a constant state of change.

\section{Classifying Classification Systems}

The idea of classifying existing classification systems are to present a more holistic view of existing classification systems - providing guidance for the implementation of classification systems and provide the basis of future classification systems. Here, it is split into two major categories, "International, Domestic and Inter-Industry Classification System" and "Construction/Building Entities and Contractor Classification System".

\section{International, Domestic and Inter-Industry Classification System}

This classification is divided by industry and/or the wider research communities to form acceptable international and domestic classifications for the industry - by research unified-international classification, by countryinternational classification and by country-specific regulative body. Classification systems such as the CICS, EICS, ISO/DIS 12006-3, IAI-IFC, UNSPSC and OmniClass are clustered into a single type of classification, where the system is derived from research and development by international bodies and associations. These classification systems can be adopted and used internationally. Country-international classifications are systems created specially in each country, tailored to the specific national needs. This is represented through $\mathrm{CI} / \mathrm{SfB}$, Uniclass and CAWS as used in the United Kingdom, STABU LexiCon in Netherlands, POSC/Caesar and BARBi in Norway, SfB and BSAB in Sweden and MasterFormat for North America. Country-specific regulative body classification is enforced exclusively in each country, such as those imposed by the BCA in Singapore, HBS of New South Wales in Australia, CSLB of California in the USA and the Works Branch of Hong Kong SAR. Another method of classification, led by consumers, is shown in the production of the Yellow Pages directory worldwide; where the construction industry in different countries shapes its own the classification system. These arrangements can be seen in Figure 1. 

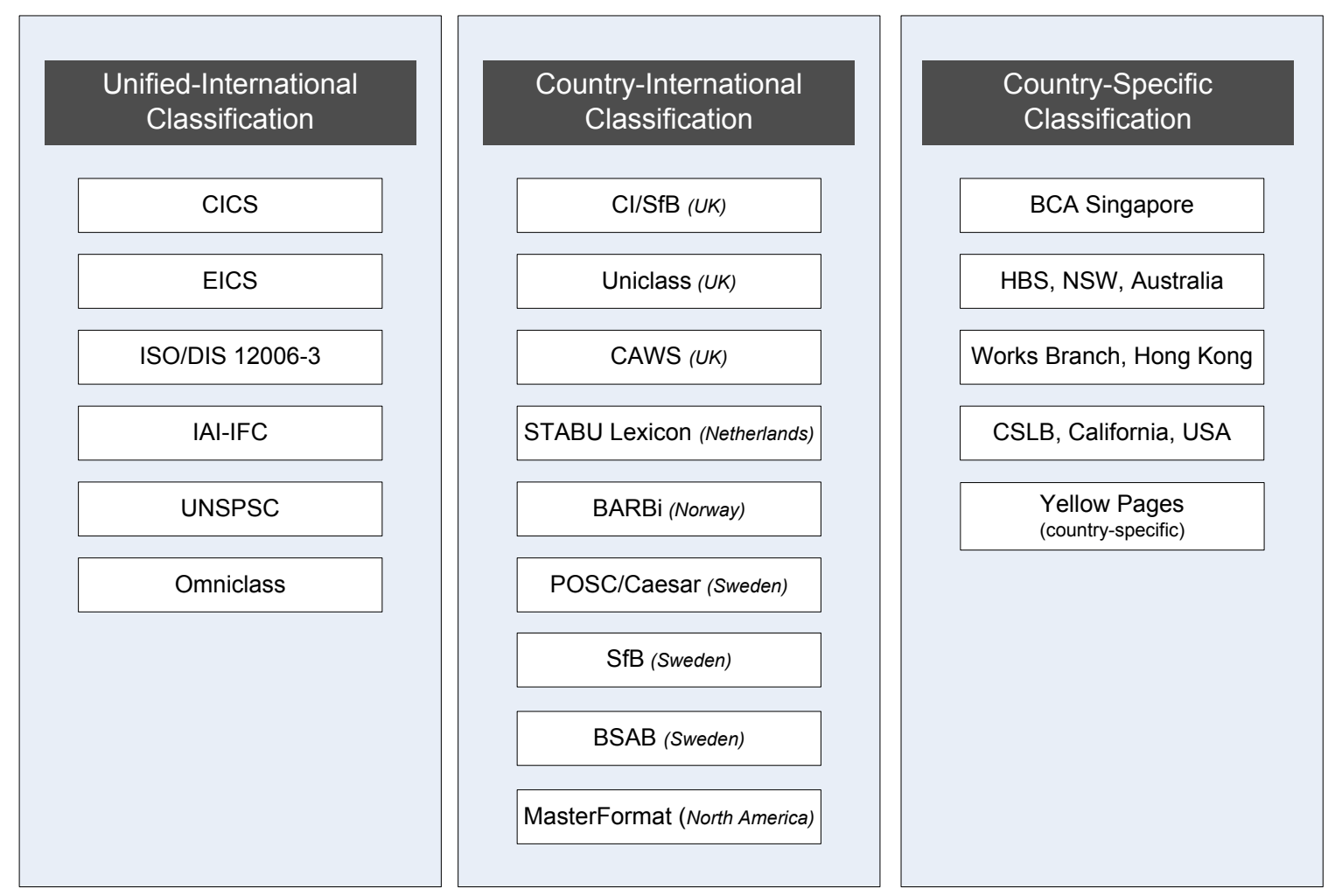

Figure 1 : International, domestic and inter-industry classification systems.

\section{Construction/Building Entities and Contractor Classification System}

This category presents classifications by construction/building entities and by contractor. The classification by construction/building entities are further split into manual referencing system and the electronic referencing system; the classification by contractors are also split by contractor work specialisation and by combination of capabilities. The construction/building entities manual referencing systems dominate - this is preferred in classifications such as the $\mathrm{CI} / \mathrm{SfB}$, Uniclass, CAWS, SfB, BSAB, MasterFormat, UNSPSC, OmniClass, CICS, EICS and in the Yellow Pages; while classification by electronic referencing systems are shown in STABU LexiCon, POSC/Caesar, BARBi, ISO/DIS 12006-3 and in the IAI-IFC. Contractor classification by work specialisation is practiced by the HBS of New South Wales in Australia and CSLB of California in the USA. Contractor classification by the BCA in Singapore and the Works Branch of Hong Kong are meticulous as they combine stringent rules in work specialisation, financial capabilities and ISO qualifications in their system. These arrangements can be seen in Figure 2. 


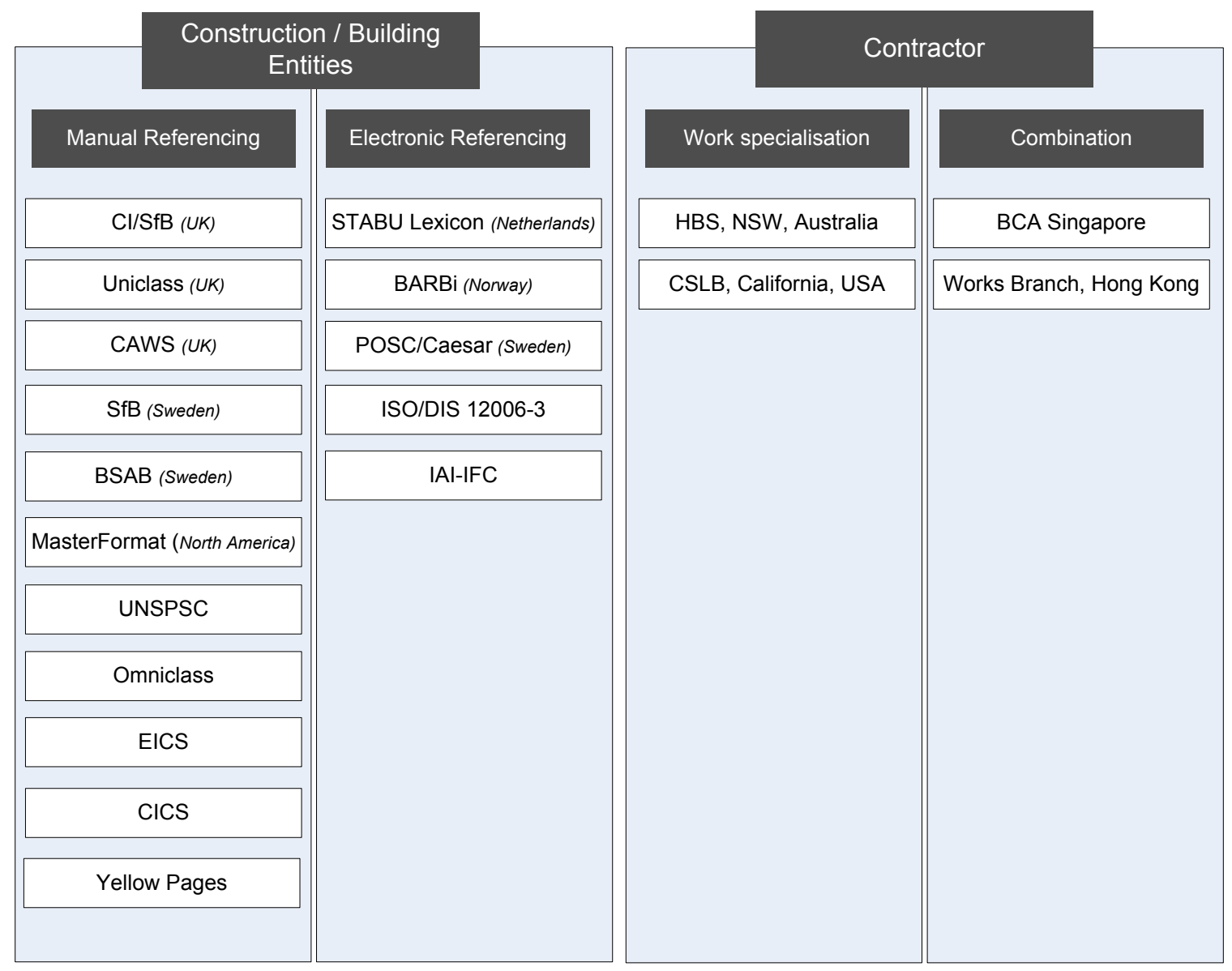

Figure 2 : Construction/Building entities and contractor classification systems.

\section{Classification Analysis}

Radar diagrams, based on the graphical concept of a radar screen for tracking ships or airplanes, can be drawn for any combination of perspectives and criteria to suit any needs (Bitman and Sharif, 2008). The radar diagram shows elements which fall within the acceptable range and which do not. This research uses the radar diagram as a diagnostic tool to evaluate the level of strengths, weaknesses and exclusivity of classification system. The areas plotted through the radar diagram represent the areas of specialisation and/or advantages (or lacking of) each classification system, when compared to each other. From the diagrams, it is possible to extract the best practices from existing classification system, and assist in the formation of in future 'best-of-breed' classification system.

The assessment, appraisal and evaluation of the classification systems are split into six different categories, each defining its characteristics - ease of use; easy up-take; expandability; compatibility; depth; acceptance. Each characteristics are then rated in a maturity model of one (1) being the lowest score and five (5) being highest.

- Simplicity and user-friendliness of the system dictates the ratings for the 'ease of use' of the system, the presentation of a simple interface between the users and the classification system. This is essential to provide maximum information to the user at a glance.

- 'Easy up-take' relates to the adoption of the system for any user or - how simple it is to use the classification system? Manual systems are generally easier to adopt then the complex electronic systems.

- The ability for the system to expand and evolve in the future is fundamental to be kept updated with the current construction evolution. This is appraised in the 'expandability' section.

- The system must be able to be compatible with other existing systems for inter-system integration; this is rated under the 'compatibility' characteristics. 
- 'Depth' considers the details, features and specification of the system. A more detailed system rates higher than a simplified classification.

- The use, recognition and acknowledgment of the system is measured in the 'acceptance' section of the assessment, representing the level of acceptance of the system by the international or local construction communities; industry or research communities.

The radar diagram framework and weightings are as shown in Figure 3.

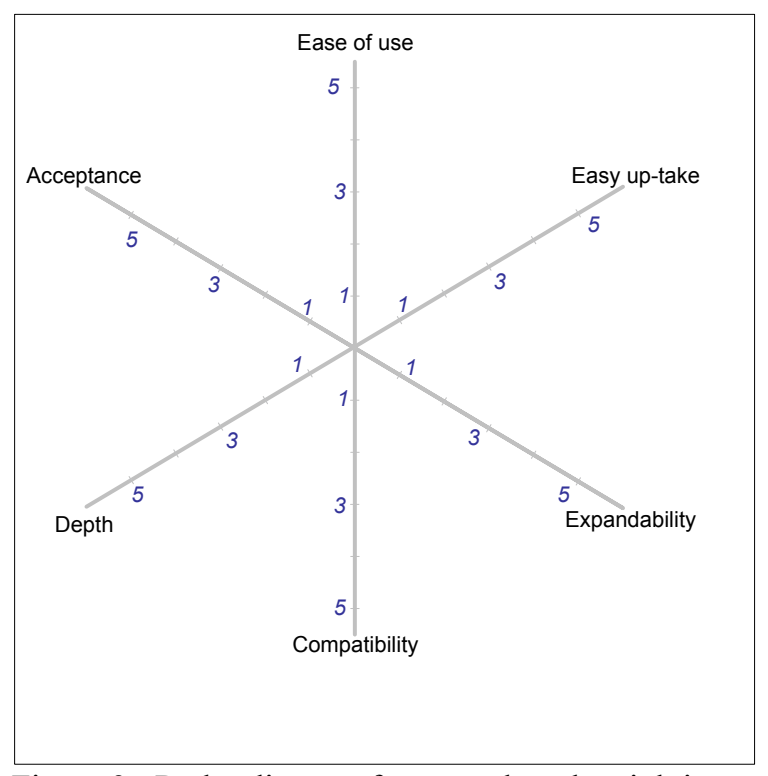

Figure 3 : Radar diagram framework and weightings.

A generic scoring system is given to demonstrate the strengths and weaknesses of each classification system. Consultations sessions were undertaken with the Construction Industry Development Board (CIDB) of Malaysia. CIDB Malaysia is established as a regulated body entrusted with the responsibility of coordinating the needs and wants of the Malaysian construction industry, planning the direction of the industry, addressing the pertinent issues and problems faced by the industry and make recommendations in the formulation of policies for the industry. Five different consultations were held with the senior management of CIDB to provide feedback and assist in scoring, as demonstrated in Table 1. Samples of the completed diagram are as shown in Figures 4 and 5. This exercise was undertaken as part of CIDB's internal assessment of current contractor registration in Malaysia.

\begin{tabular}{|l|c|c|c|c|c|c|}
\cline { 2 - 6 } \multicolumn{1}{c|}{} & $\begin{array}{c}\text { Ease of } \\
\text { use }\end{array}$ & $\begin{array}{c}\text { Easy up- } \\
\text { take }\end{array}$ & $\begin{array}{c}\text { Expand- } \\
\text { ability }\end{array}$ & $\begin{array}{c}\text { Compa- } \\
\text { tibility }\end{array}$ & Depth & $\begin{array}{c}\text { Accept- } \\
\text { ance }\end{array}$ \\
\hline BCA, Singapore & 4 & 4 & 3 & 1 & 5 & 3 \\
\hline HSB, NSW, Australia & 5 & 1 & 1 & 1 & 2 & 3 \\
\hline CSLB, California, USA & 5 & 3 & 2 & 1 & 2 & 3 \\
\hline Works Branch, Hong Kong & 4 & 4 & 3 & 1 & 5 & 3 \\
\hline CI/SfB (UK) & 4 & 4 & 3 & 4 & 2 & 5 \\
\hline Uniclass (UK) & 3 & 5 & 3 & 3 & 3 & 3 \\
\hline CAWS (UK) & 5 & 3 & 3 & 3 & 4 & 4 \\
\hline STABU LexiCon (Netherlands) & 2 & 1 & 5 & 4 & 5 & 3 \\
\hline POSC/Caesar (Norway) & 1 & 1 & 5 & 3 & 5 & 2 \\
\hline BARBi (Norway) & 2 & 2 & 5 & 4 & 5 & 3 \\
\hline SfB (Sweden) & 5 & 5 & 1 & 4 & 2 & 5 \\
\hline
\end{tabular}




\begin{tabular}{|l|l|l|l|l|l|l|}
\hline BSAB (Sweden) & 4 & 4 & 4 & 3 & 3 & 3 \\
\hline MasterFormat (North America) & 3 & 4 & 5 & 3 & 4 & 4 \\
\hline Yellowpages & 5 & 3 & 3 & 2 & 5 & 5 \\
\hline CICS & 4 & 4 & 2 & 2 & 3 & 2 \\
\hline EICS & 4 & 3 & 2 & 2 & 3 & 2 \\
\hline UNSPSC & 5 & 3 & 5 & 3 & 4 & 4 \\
\hline ISO/DIS 12006-3 & 1 & 5 & 5 & 4 & 5 & 4 \\
\hline IAI-IFC & 1 & 3 & 5 & 4 & 5 & 4 \\
\hline OmniClass & 3 & 3 & 4 & 4 & 5 & 4 \\
\hline
\end{tabular}

Table 1 : Classification systems score.

The national classification systems as used by the BCA, HSB, CSLB and Works Branch score highly in the in the simplicity section, thus, achieving the aim of being simple yet informative. However, these systems are not compatible as it is produced specifically in national interest, low tolerance for change or expandability, while the acceptance is compulsory in every country. Classification by the BCA and Works Branch are especially in depth, with strict pre-registration requirements, personnel counts, ISO qualifications, and health and safety regulations. This makes these country-specific classifications rigid, not compatible but simple to update.

The older country-international classification, such as $\mathrm{SfB}$ and $\mathrm{CI} / \mathrm{SfB}$, scores highly in its ease of use, easy uptake, acceptance and compatibility, but very low in depth and expandability. Created about 20 years ago, these systems form the foundations for the more recent classification systems available today. Due to its low acceptance for expandability, the use of the systems was eventually phased out and replaced by other more detailed and complex classification.

The Uniclass and CAWS classification are evolution systems from the $\mathrm{CI} / \mathrm{SfB}$ in the UK. Both these systems are manually referenced and have similar capabilities to expand and evolve its classification for the future; score relatively high in depth and acceptance. The Uniclass is easier for up-take by contractors while the CAWS us easier to use. BSAB from Sweden is based in ISO standards, focused for the Swedish construction industry. This classification forms an ideal balance between the ease of use, easy up-take and expandability, but imperfect in terms of compatibility, depth and acceptance - reflecting basis of BSAB of being a national Swedish initiative. Similarly, the worldwide Yellowpages is an industry driven directory controlled by suppliers, thus, its low expandability and poor compatibility with other systems, but gaining much in the ease of use, depth and acceptance. This directory is regarded as one of the oldest and most popular informational directory in the world.

Research-driven classifications such as the CICS and EICS are both fairly similar; difference being the CICS is for construction works and EICS for engineering works. Its expandability is limited due to its fixed facets and format, poor compatibility to other systems and low acceptance by the industry. More recently developed classifications such as the MasterFormat, UNSPSC and OmniClass offer a more complete and widely accepted system. These classifications are open, offering global electronic commerce standards that provide a logical framework throughout the global marketplace and supply chain. Perhaps the most obvious change is the specific provisions for expandability in the future, highly specific and easy up-take of the system. The only drawback is the MasterFormat system is developed and used widely only in North America; the UNSPSC and OmniClass have worldwide audiences.

Electronic classifications such as STABU LexiCon, POSC/Caesar and BARBi rate almost similar to each other. All being difficult to use and complicated to up-take due to its electronic nature. On the other hand, it holds the advantage of unlimited expandability, depth and compatibility as these classification systems can be rewritten, reedited and modified to accommodate future changes for the industry. The acceptance of the systems is nominal as all systems are developed in national interest.

The ISO/DIS 12006-3 and IAI-IFC classifications are electronic classifications and have similar characteristics. With the exception that both these systems are united-international classifications, developed, received and acknowledged by experts worldwide. Despite being a complex system, both the ISO/DIS 12006-3 and IAI-IFC have extremely high expandability, compatibility, depth and up-take. Bring an electronic classification system, all entities can be customised, amended and improved to be implemented in any nation or organisation globally. 


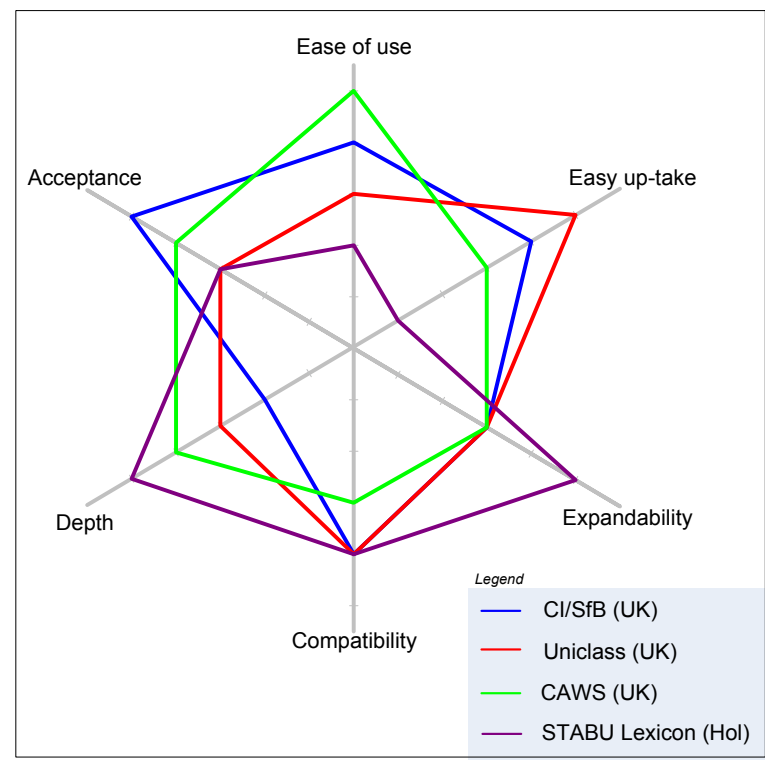

Figure 4 : Radar diagram for $\mathrm{CI} / \mathrm{SfB}$, Uniclass, CAWS and STABU Lexicon classification systems.

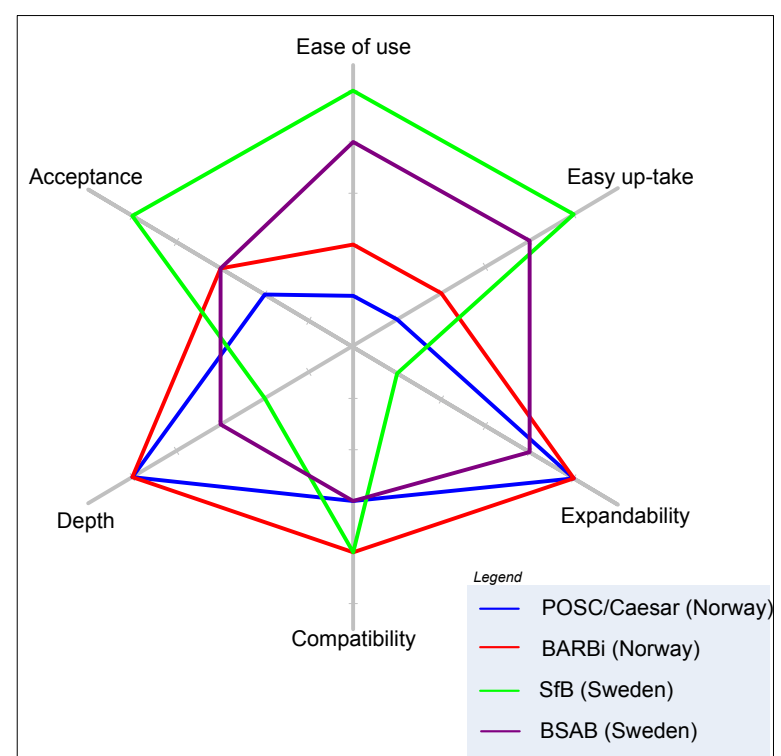

Figure 5 : Radar diagram for POSC/Caesar, BARBI, $\mathrm{SfB}$ and BSAB classification systems.

\section{The Way Forward}

This paper analysed the structure, scope and direction of development of different architecture, engineering and construction (AEC) classification systems, and to investigate the possibilities of coordination and cooperation between them for its adoption. Further research will be needed with other participants in the AEC industry, from governments and private businesses, to obtain their views and approach in their classification system. Consensus from governments and businesses could lead to a universally accepted classification system.

\section{Conclusion}

The ever changing AEC industry is facing its most critical phase, the immense growth of computing and information technology is changing. The classification of the industry is a timely measure to embark upon the rapidly increasing demands for information, constantly changing products, technology, techniques and technical solutions. The islands of automation and product specification caused by the fragmented construction industry do not help.

The need to classify classification systems is apparent to present a holistic, yet specific view of existing systems, in proving guidance for implementation and provide the basis of future classification systems. This study provides two major categorisations. The first being the International, Domestic and Inter-Industry Classification - the classification systems were divided by industry and/or research community to form acceptable international and domestic classifications for the industry, by research unified-international classification, by country-international classification and by country-specific regulative body. The second categorisation is the Construction/Building Entities and Contractor Classification System - this presents classifications by construction/building entities and by contractor. The classification by construction/building entities are further split into manual referencing system and the electronic referencing system; the classification by contractors are also split by contractor work specialisation and by combination of capabilities.

Assessment, analysis and appraisals are conducted on the classification systems. This is split into six different categories, each defining its ease of use; easy up-take; expandability; compatibility; depth; acceptance. Each characteristics are then rated in a maturity model of one (1) being the lowest score and five (5) being highest. The scores indicate that national classification systems as used by the BCA, HSB, CSLB and Works Branch are highly simple to use and accepted, but are highly incompatible, poorly expandability. This makes these country-specific classifications rigid, not compatible but simple to update. The older country-international classification, such as 
$\mathrm{SfB}$ and $\mathrm{CI} / \mathrm{SfB}$, scores highly in its ease of use, easy up-take, acceptance and compatibility, but very low in depth and expandability. The Uniclass and CAWS are rated relatively high in depth and acceptance; the Uniclass is easier for up-take by contractors while the CAWS us easier to use. BSAB from Sweden forms an ideal balance between the ease of use, easy up-take and expandability, but imperfect in terms of compatibility, depth and acceptance. Similarly, the worldwide Yellowpages is rated low in expandability and poor compatibility with other systems, but gaining much in the ease of use, depth and acceptance. Research-driven classifications (CICS and EICS) are fairly similar; its expandability is limited, poor compatibility, leading to low acceptance by the industry. The newly developed classifications such as the MasterFormat, UNSPSC and OmniClass offer a more complete and widely accepted system, which provides provisions for expandability, highly specific and easy up-take. The only drawback is the MasterFormat system is developed and used widely only in North America; the UNSPSC and OmniClass have worldwide audiences. Electronic classifications such as STABU LexiCon, POSC/Caesar and BARBi rate almost similar to each other; all being difficult to use and difficult to up-take, but it has the advantage of unlimited expandability, depth and compatibility as these classification systems can be rewritten, re-edited and modified to accommodate future changes for the industry. The ISO/DIS 12006-3 and IAI-IFC classifications are developed, received and acknowledged by experts worldwide. These systems have extremely high expandability, compatibility, depth and up-take.

The idea of the 'ultimate classification system' is a utopia. With rapidly increasing demands for information, constantly changing products, technology, techniques and technical solutions, and the islands of automation and product specification caused by the fragmented construction industry do not help. Computer based information management introduces new possibilities and puts partly new requirements on information and classification systems. The way forward is the further research into a global unified classification system which could be used by all. The closest sample to this will be the UNSPSC classification, but further work is needed on its strengths, weaknesses and exclusivity to enable it to be globally used and accepted. 


\section{References}

Abeysekera, I. and Guthrie, J. (2004), “Human capital reporting in a developing nation”, The British Accounting Review, 36(3), 251-268.

BCA (2007), BCA Contractors Registry, Building and Construction Authority (BCA), Singapore. http://dir.bca.gov.sg/bca/index.asp [Accessed 1 August 2007].

Bell, H., Bjørkhaug, L. and Rønning, J. (2004), "ICT-Platform for Object Oriented Knowledge in the Building and Construction Industry", B4E Conference Building for a European Future, Maastricht, Netherlands.

Bitman, W.R. and Sharif, N. (2008), “A Conceptual Framework for Ranking R\&D Projects”, IEEE Transactions on Engineering Management, 50(2).

Broughton, V. (2006), "The need for a faceted classification as the basis of all methods of information retrieval", ASLIB Proceedings: New Information Perspectives, 58(1/2), 49-72.

Chan, P.W., and Kaka, A. (2007), "Productivity improvements: understand the workforce perceptions of productivity first", Personnel Review, 36(4), 564-584.

Chang, A.S.T. and Tsai, Y.W. (2003), "Engineering Information Classification System", Journal of Construction Engineering and Management, 129(4), 454-460.

Contractors State License Board (2007), Description of Classification, Contractors State License Board, California, USA. http://www.cslb.ca.gov/forms/GClass.pdf [Accessed 1 August 2007].

Construction Project Information (CPI) (1987), Common Arrangement of Work Section for Building Works (CAWS), 2nd Edition, Construction Project Information Committee, ISBN: 9780951266250

Cotton, B. and Oliver, R. (1994), The Cyberspace Lexicon: An Illustrated Dictionary of Terms from Multimedia to Virtual Reality, Phaidon Press Ltd.

Crawford, M., Cann, J. and O"Leary, R. (1997), Uniclass : Unified Classification for the Construction Industry, RIBA Publications, London.

Giertz, L. M. (1995), “Integrated Construction Information Efforts Since 1945”, Integrated Construction Information, E\&FN Spon, London.

Hoare, P. (1998), "The development of a European information society", Library Review, 47(8), $377-382$.

Home Building Service (2007), Licence categories, Home Building Service, New South Wales, Australia. http://www.fairtrading.nsw.gov.au/building/builderstradespeople/licencecate go ries.html [Accessed 1 August 2007].

IAI-IFC (2007), IFC2x Edition 2 Addendum 1. International Alliance for Interoperability - Industry Foundation Classes. http://www.iai-international.org/Model/R2x2_add1/index.html [Accessed 2 August 2007].

ISO (2007), ISO 12006-3:2007 Building construction - Organization of information about construction works - Part 3 : Framework for object-oriented information, 91.010.01., Secretariat, Norway.

Kang, L.S. and Paulson, B.C. (1997), "Adaptability of Information Classification Systems for Civil Works", Journal of Construction Engineering and Management, 123(4), 419-426.

MasterFormat ${ }^{\mathrm{TM}}$ (2004), 2004 Edition Numbers and Titles, Construction Specifications Institute and Construction Specifications Canada, 2004 Edition, Canada.

McCulloch, E. (2004), "Multiple terminologies: an obstacle to information retrieval", Library Review, 53(6), 297-300.

OCCS (2001), The Overall Construction Classification System, A Strategy for Classifying the Built Environment, Preliminary draft for review and comment, Ontario, Canada.

OmniClass $^{\mathrm{TM}}$ (2006), Strategy for Classifying the Built Environment : Introduction and User"s Guide, Edition 1.0, Release 2006-03-28, Ontario, Canada.

Phua, F.T.T. and Rowlinson, S. (2004), "How important is cooperation to construction project success? A grounded empirical quantification", Engineering, Construction and Architectural Management, 11(1), 45-54.

POSC (2007) POSC Specifications v2.2, Petrotechnical Open Software Corporation. Available from : http://www.posc.org/Epicentre.2 2/SpecViewer.html [Accessed 2 August 2007].

Ray-Jones, A. and Clegg, D. (1991), Cl/SfB Construction Indexing Manual, RIBA Publishing, London.

Saeed, H. and Chaudhry, A.S. (2002), "Using Dewey decimal classification scheme (DDC) for building taxonomies for knowledge organisation", Journal of Documentation, 58(5), 575-583.

SB-Rekommendationer (1987), BSAB - systemet. Tabeller och tillämpningar (The BSAB System. Tables and Applications), Swedish Building Centre, Stockholm.

UNSPSC (2007), United Nations Standards Products and Services Codeset, UNSPSC V9.1201, United Nations Development Programme (UNDP).

van Rees,R. (2003), "Clarity in the usage of the terms ontology, taxonomy and classification", CIB workgroup 78 Conference, Auckland, New Zealand.

Wong, C.H., Nicholas, J. and Holt, G.D. (2003), "Using multivariate techniques for developing contractor classification models", Engineering, Construction and Architectural Management, 10(2), 99-116.

Works Branch, Development Bureau (2007), Consultants and Contractors, Government of Hong Kong Special Administrative Region http://www.devb-wb.gov.hk/consultants and contractors/contractors/index.aspx? langno=1andno deid=620 [Accessed 1 August 2007]. 